\title{
Morphological changes of Dachan Bay in Pearl River Estuary based on RS and DEM
}

\author{
Rongyao Ji, Yongjun Lu, Zhili Wang, Siping Mo \\ State's Key Laboratory of Hydrology Water Resources and Hydraulic Engineering Science, \\ Nanjing Hydraulic Research Institute, Nanjing, China
}

\begin{abstract}
The surrounding area of the Dachan Bay in the Pearl River Estuary has one of the highest economic development rates of China. Rapid industrialization and urbanization has resulted in extensive changes in land use, including the tidal flat reclamation and harbor construction. For the analysis of the morphological changes of the Dachan Bay, multi-temporal Landsat images have been digitized by using the integrated RS and GIS technique, and the digital elevation modes in different years were set up in combination with topographical and nautical data. From the change analysis, it can be concluded that the sea area of the Dachan Bay decreases to $6.0 \mathrm{~km}^{2}$, by $87.6 \%$ between 1907a and 2011a due to the large-scale tidal flat reclamation, and the maximum downcutting depth of the seabed in the entrance area is over $10 \mathrm{~m}$ mainly caused by extensive harbor construction. Based on the research of the morphological change in recent decades, it is suggested that the human activities have become one of the major factors affecting the morphological processes of the Dachan Bay.
\end{abstract}

Keywords-Morphological change; harbor construction; tidal flat reclamation; remote sensing; Digital elevation model

\section{INTRODUCTION}

The Pearl River, the largest river in southern China, empties directly into Lingding Bay through four outlets, and ultimately into the South China Sea. Consequently, Lingding Bay, with the area of $2000 \mathrm{~km}^{2}$, is actually the largest estuary of the Pearl River. The four outlets, such as Humen, Jiaomen, Hongqimen and Hengmen, are located close together in the North-Western part of the bay, and the secondary Dachan Bay is located in the middle part of the east coast (Figure 1). The surrounding area of the Dachan Bay, the Pearl River deltaic area, is one of the most prosperous economic regions in China. In the last two decades the Province's GDP grew at an average annual rate of over $10 \%$. Total import and export value of Guangdong Province account for about 1/3 of mainland China. The rapid industrialization and urbanization in the Dachan Bay area has resulted not only in extensive changes in land use, but also in the loss of significant amounts of agricultural land, and led to several environmental problems, such as land subsidence, intrusion of sea water, siltation of channels and coastal erosion.

Knowledge of the topography and coastline is the basis for measuring and characterizing land and water resources. Coastal zone mapping and change detection are essential for safe navigation, resource management, environmental protection, and sustainable coastal development and planning. The enormous development speed of the Dachan Bay area makes it difficult to detect most of the coast changes in time by traditional measurements. However, integrating remote sensing and GIS can be an effective tool to map the changes in a fast and effective way (Chen, 1998; El-Asmar, 2002; Chong, 2004, Hernecke, 2004).

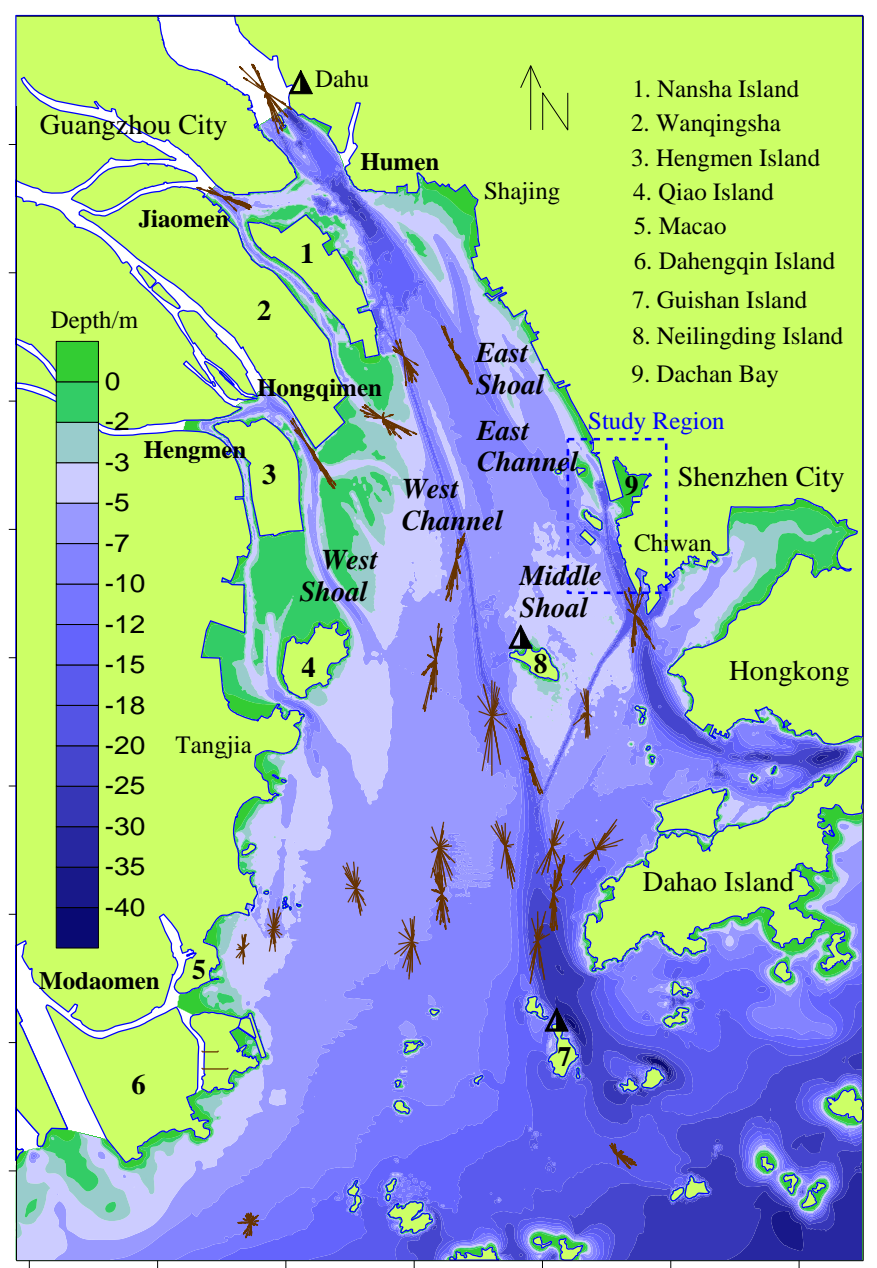

Figure 1. Location of the Dachan Bay in the Lingding Bay

Examples of studies to detect coast changes in China with remote sensing are from the Yellow River delta ( $\mathrm{Li}$ et al., Chang et al., 2004), the Bohai sea (Jiang, et al., 2003; Huang and Fan, 2004; Ji et al., 2011) and the Fujian coast (Sun and Zhang, 2004). Also from the Pearl River delta successful studies (Li and Yeh, 1998, Li and Damen, 2010; Ji et al., 2012) have been carried out on coast change and urban expansion 
using multi-temporal satellite images. These studies show that most of the coast change is caused by human activities such as large-scale tidal flat reclamation and the construction of the harbors and cities.

\section{RESEARCH METHODOLOGY AND DATA USED}

The research methodology includes the following steps: a) data collection, b) image data processing and 3) digital analysis of the coast changes in time (Figure 2).

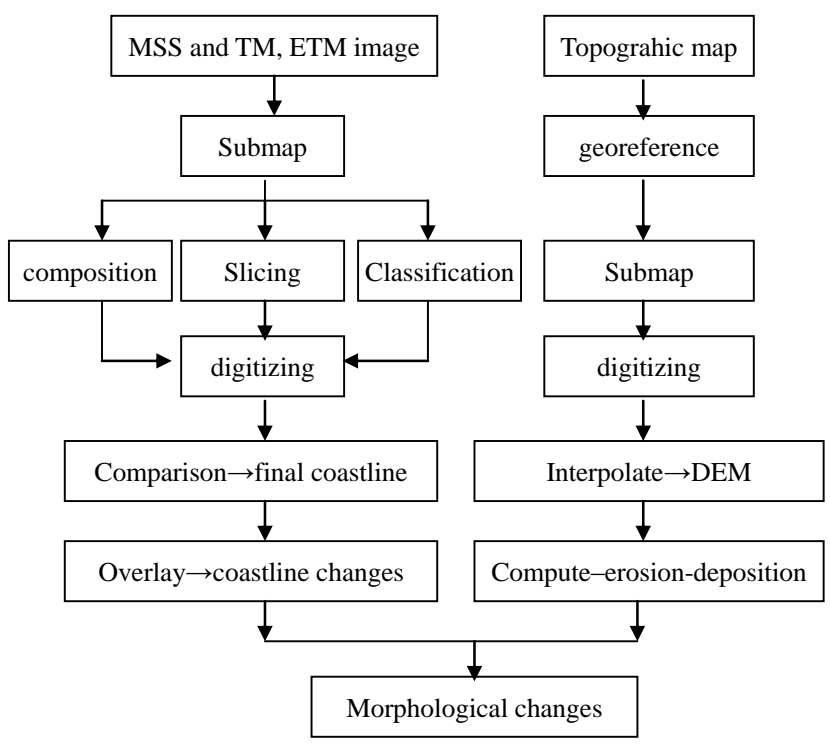

Figure 2. Flowchart of research procedure

\section{A. Data collection}

Multitemporal remote sensing data of Landsat image from 1978 to 2011, totaling twenty scenes were used in this research. Imagery pre-1984 is MSS data and since 1984 is TM and ETM data. The spatial resolution of TM (ETM) and MSS data are 30 $\mathrm{m}$ and $80 \mathrm{~m}$, respectively. Also available was the topographic map of 1907, 1950, 1989, 1998, 2002, 2008, 2009 and 2011. Tidal data from the time of acquisition of the images was also collected.

\section{B. Image data pre-processing}

Image pre-processing is the process of making images more interpretable for a particular application. Geometric correction, false color composition, image mosaic and submap were used in the paper. The Landsat images were already georeferenced, but the scanned topographic maps were not. Therefore they were georeferenced to the Landsat image, in order to keep the same UTM coordinate system. The accuracy was controlled to 0.5 grids $(1$ grid $=30 \mathrm{~m} \times 30 \mathrm{~m})$. This task was carried out using ArcGIS for Windows operating system.

Different band false color combinations were tested for coastline extraction by ENVI software. It is found that bands 7, 4, 2 for RGB was found to be most effective for mapping coastline, while the bands 3, 2, 1 for RGB to be most effective for suspended material. The coastline can be defined as the boundary between water and land. As the reflectance of water in near infrared is much lower than of land cover, band 5 of Landsat ETM and TM image, band 4 of Landsat MSS image are selected for the binary slicing to define the coastline. It is found that the slicing map usually is better than composition image for digitalizing coastline, especially in some wetlands. Five classes of built-up area, water, forest, plantation and bare land have been classified for the Landsat image.

\section{Digital analysis}

After the coastlines were extracted from Landsat image, as well as from topographic map, they were overlaid in ArcGIS for detecting their changes in the period. Standard GIS measurement tools (ArcGIS) are easily used to determine composite changes (accretion and erosion) when asynchronous coastlines are digitally overlaid, registered and compared to the initial shoreline. These measurements enable precise calculation of the distance, accretion area, and erosion area due to shoreline movement in the period between different image acquisitions.

The bathymetric map of the study area was prepared, and the terrain data and contours was digitized. By the interpolation of ArcGIS software, the digital elevation model of the Dachan Bay (DEM) was generated to obtain the underwater bathymetric features, for example in 2002a and 2009a (Figure 3 and Figure 4). Based on the digital elevation model in different years, the seabed erosion-deposition can be calculated between different years.

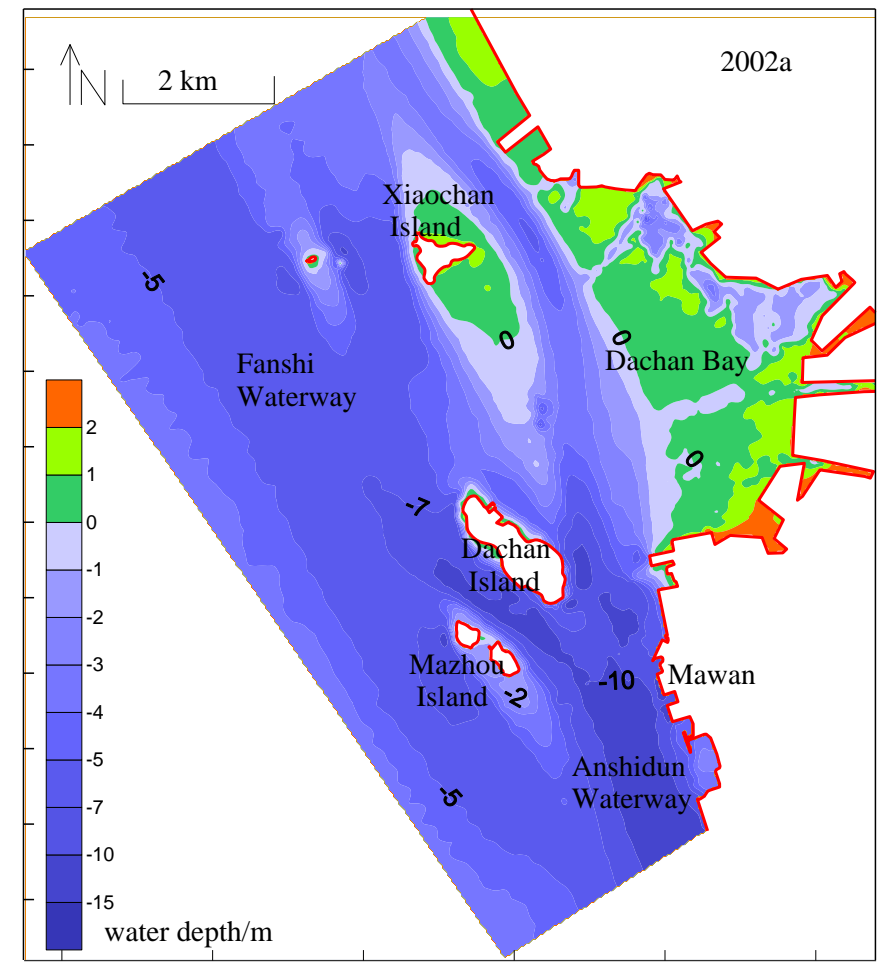

Figure 3. Digital elevation model of the Dachan Bay in 2002 


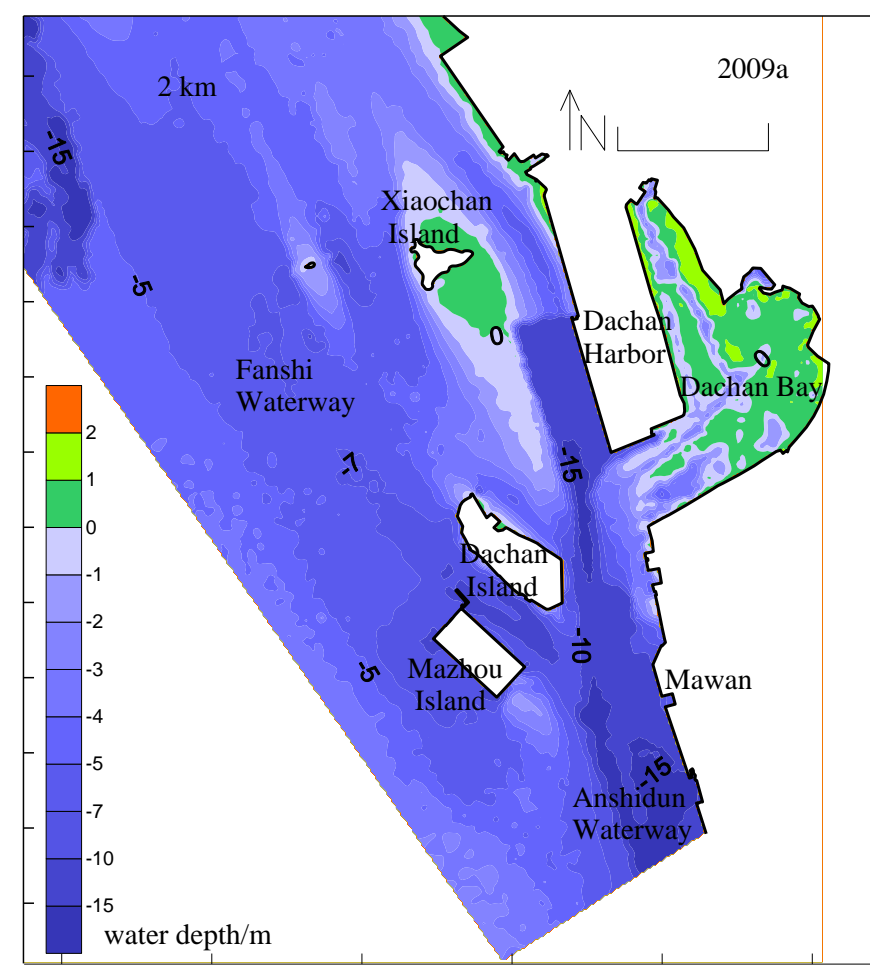

Figure 4. Digital elevation model of the Dachan Bay in 2002

\section{MORPHOLOGICAL CHANGES IN RECENT DECADES}

\section{A. COASTLINE CHANGES}

The resulting coastline vector maps (Figure 5) show that the coastline along the entire Dachan Bay changed considerably during the period 1907 to 2011 .

In 1907, The Dachan Bay was a semi-circle bay which was about $10 \mathrm{~km}$ wide in the entrance and $48.35 \mathrm{~km}^{2}$ of water area, and has been shrinking obviously due to the effects of human activities, such as tidal flat reclamation and harbor development. The water area of the Dachan Bay decreased to $38.33 \mathrm{~km}^{2}$ in $1950,31.98 \mathrm{~km}^{2}$ in $1978,25.79 \mathrm{~km}^{2}$ in 1988 , $16.18 \mathrm{~km}^{2}$ in 1999 , and $13.12 \mathrm{~km}^{2}$ in 2002 . Especially after 2005, the Dachan Bay developed rapidly into an important harbor zone. In 2011, The Dachan Bay was only about $1.0 \mathrm{~km}$ wide in the entrance and $6.0 \mathrm{~km}^{2}$ of water area.

Due to human activities, the large-scale intertidal zone was reclaimed, which resulted in the rapid decrease of water area in Dachan Bay, about $42.35 \mathrm{~km}^{2}$ in total over the past 104 years, by $87.6 \%$ between $1907 \mathrm{a}$ and $2011 \mathrm{a}$. The decrease rate of the Dachan Bay area is different obviously in different stages. Reclamation area of the Dachan Bay increased by $16.37 \mathrm{~km}^{2}$ for the first 71 years with a $0.23 \mathrm{~km}^{2}$ annual rates, and $25.98 \mathrm{~km}^{2}$ for the last 33 years with a $0.79 \mathrm{~km}^{2}$ annual rates as a result of intensified human activities. At present, the Dachan Bay becomes a semi-closed bay, which results in the decrease of the tidal volume and the hydrodynamic conditions, and the block of water exchange.

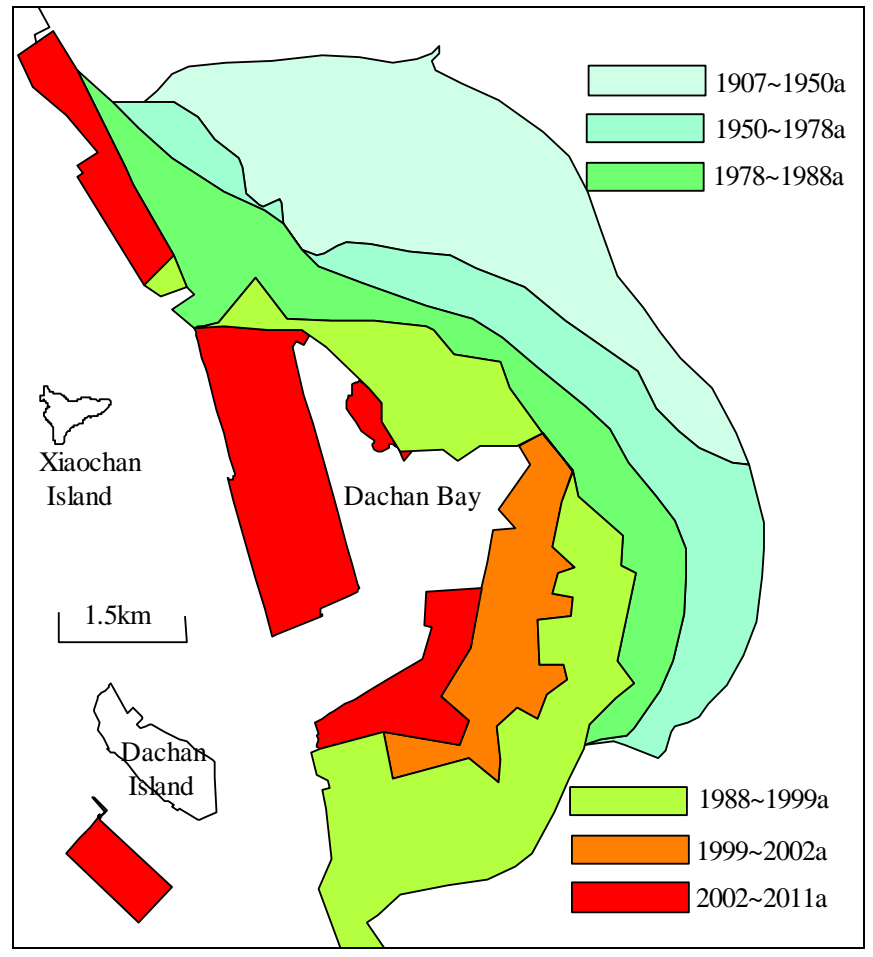

Figure 5. Coastline changes of the Dachan Bay since 1907

\section{B. SEABED CHANGES}

Based on the digital elevation model of the Dachan Bay in different years, the seabed erosion-deposition is calculated between different years (Figure 6 and Figure 7).

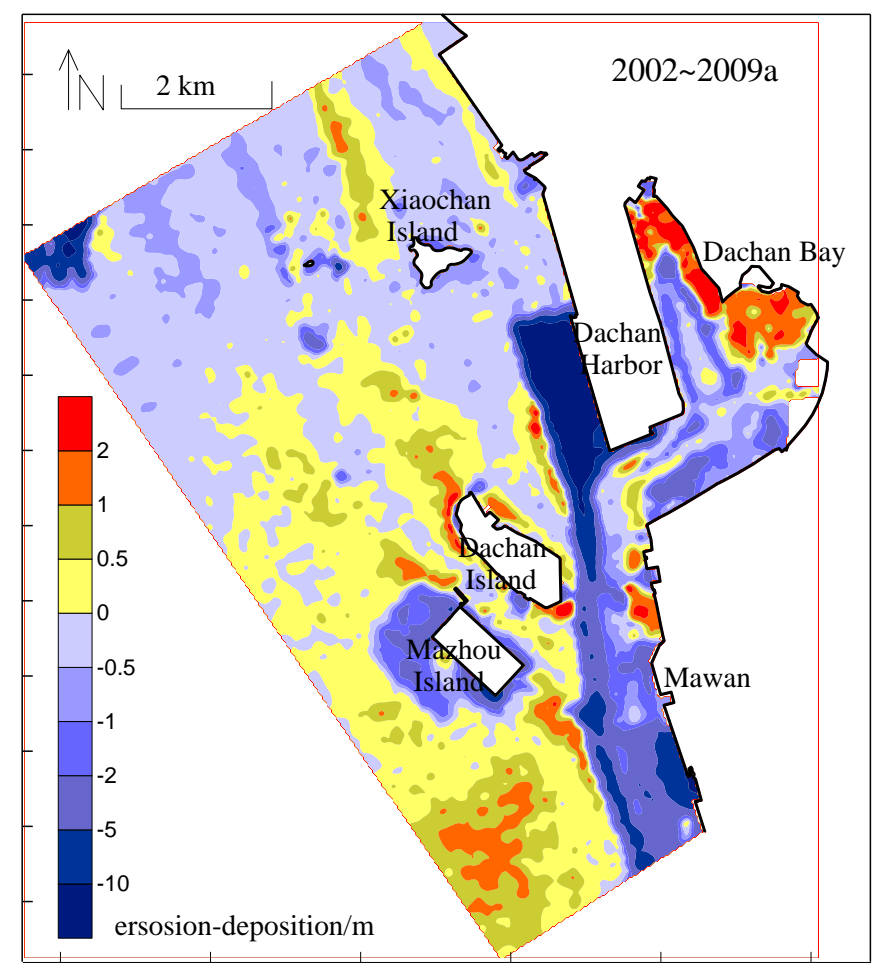

Figure 6. Distribution of erosion-deposition near the Dachan Bay between 2002 and 2009 
According to the analysis of erosion-deposition distribution from 2002 to 2009, the seabed near the Xiaochan Island has the obvious erosion trend in whole, up to $0.5 \mathrm{~m}$ in depth, and in the south-western sea area of the Dachan Island, the seabed have obvious deposition trend, up to $1 \sim 2 \mathrm{~m}$ thick. During the same periods, along the coast from the Mawan to the Dachan Harbor, the downcutting depth of the seabed exceeds over $10 \mathrm{~m}$ due to the effects of channel dredging. Within the Dachan Bay, the erosion depth of the seabed is about $1 \sim 2 \mathrm{~m}$, except the top of the bay with $2 \mathrm{~m}$ deposition thickness.

According to the analysis of erosion-deposition distribution from 2009 to 2011, and in the northern sea area of the Xiaochan Island, the seabed have slight deposition trend, up to $0.5 \mathrm{~m}$ thick, and the seabed near the Dachan Island has the slight erosion trend in whole, up to $0.5 \mathrm{~m}$ in depth. Within the Dachan Bay, deposition thickness of the seabed is about $1 \mathrm{~m}$ over the past 3 years.

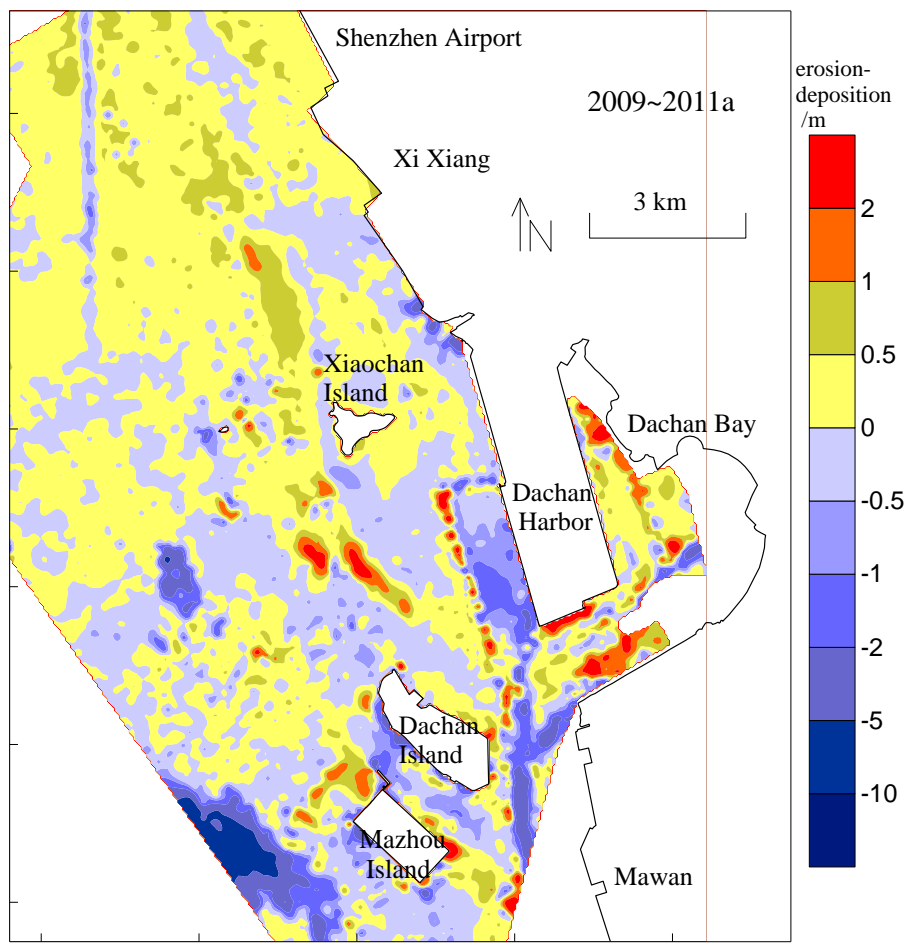

Figure 7. Distribution of erosion-deposition near the Dachan Bay between 2009 and 2011

\section{CONCLUSIONS}

Rapidly changing coast is a serious problem in many areas of the world. In recent years, the growing human activities greatly affect the natural evolution process of the coastal zone in the Dachan Bay. The study reveals that the human activities like extensive harbor construction and tidal flat reclamation play a vital role in the coast morphological changes of the Dachan Bay, in addition to natural processes. Over the past 104 years, reclamation area of the Dachan Bay increased by $42.35 \mathrm{~km}^{2}$, a $0.41 \mathrm{~km}^{2}$ annual averages increase, with a $16.37-$ $\mathrm{km}^{2}$ expansion for the first 71 years and a $25.98-\mathrm{km}^{2}$ for the last 33 years, as a result of intensified human activities. Along the coast from the Mawan to the Dachan Harbor, the downcutting depth of the seabed exceeds over $10 \mathrm{~m}$ due to the effects of channel dredging. At present, the Dachan Bay becomes a semi-closed bay, which results in the decrease of the tidal volume and the hydrodynamic conditions, and the block of water exchange.

\section{ACKNOWLEDGMENT}

This work is supported by the National Natural Science Foundation of China and NWO (Grant No. 51061130546).

\section{REFERENCES}

[1] L.C. Chen, and J.Y. Rau, "Detection of shoreline changes for tideland area using multitempral satellite images", Int. J. Remote Sensing, 1998, vol. 19, pp. 3383-3397.

[2] H.M. El-Asmar, "Short term coastal changes along DamiettaPort Said coast northeast of the Nile Delta, Egypt", Journal of Coastal Research, , 2002, vol. 18, pp. 433-441.

[3] A.K. Chong, "A case study on the establishment of shoreline position", Survey Review, 2004, vol. 37, pp. 542-551.

[4] W.G. Hennecke, "GIS modelling of sea-level rise induced shoreline changes inside coastal re-entrants - two examples from southeastern Australia", Natural Hazards, 2004, vol. 31, pp 253-276.

[5] A. Li, G. Li, L. Cao, Q., Zhang, and S. Deng, "The coast erosion and evolution of the abandoned lobe of the Yellow River Delta", Acta Geographica Sinica, 2004, vol. 59, pp. 731-737.

[6] J. Chang, G. Liu, and Q. Liu, "Dynamic monitoring of coastline in the Yellow River Delta by remote sensing", Geo-Information Science, 2004, vol. 6, pp. 94-98.

[7] Y. Jiang, L.F. Li, H. Kang, and X. Zhong, "A remote sensing analysis of coastline change along the Bohai bay muddy coast in the past 130 years", Remote Sensing for Land \& Resources, 2003, vol. 4, pp. 54-59.

[8] H. Huang, and H. Fan, "Monitoring change of nearshore zone in the Huanghe (Yellow River) Delta since 1976", Oceanologia et Limnologia Sinica, 2004, vol. 35, pp. 306-314.

[9] M. Sun, and W. Zhang, "Study on coastline remote sensing survey and application in Fujian Province", Journal of Oceanography in Taiwan Strait, 2004, vol. 23, pp. 213-219.

[10] X. Li, and A.G. Yeh, "Principal component analysis of stacked multi-temporal images for the monitoring of rapid urban expansion in the Pearl River Delta, Int. J Remote, 1998, vol. 19, pp. $1501-1518$.

[11] X. Li, and M.C.J. Damen, "Coastline change detection with satellite remote sensing for environmental management of the Pearl River Estuary, China”, Journal of Marine Systems, 2010, vol. 82, pp. 554-561.

[12] Y. Lu, R. Ji, and L. Zuo, "Morphodynamic responses to the deep water harbor development in the Caofeidian sea area, China's Bohai Bay", Coastal Engineering, 2009, vol. 56, pp. 831-843.

[13] R. Ji, Y. Lu, L. Jia, Z. Wang, Monitoring changes of coastal zone in Lingding Bay by integrating remote sensing (RS) and GIS. RSETE2012,

[14] R. Ji, Y. Lu, and L. Zuo. Coastline change detection of the Bohai Bay using satellite remote sensing. RSETE2011, P168171 